\title{
The effect of a dynamic background albedo scheme on Sahel/Sahara precipitation during the mid-Holocene
}

\author{
F. S. E. Vamborg ${ }^{1,2}$, V. Brovkin ${ }^{2}$, and M. Claussen ${ }^{2,3}$ \\ ${ }^{1}$ International Max Planck Research School on Earth System Modelling, Hamburg, Germany \\ ${ }^{2}$ Max Planck Institute for Meteorology, KlimaCampus, Hamburg, Germany \\ ${ }^{3}$ Meteorological Institute, Hamburg University, KlimaCampus, Hamburg, Germany
}

Received: 7 October 2010 - Published in Clim. Past Discuss.: 29 October 2010

Revised: 25 January 2011 - Accepted: 27 January 2011 - Published: 28 February 2011

\begin{abstract}
We have implemented a new albedo scheme that takes the dynamic behaviour of the surface below the canopy into account, into the land-surface scheme of the MPI-ESM. The standard (static) scheme calculates the seasonal canopy albedo as a function of leaf area index, whereas the background albedo is a gridbox constant derived from satellite measurements. The new (dynamic) scheme additionally models the background albedo as a slowly changing function of organic matter in the ground and of litter and standing dead biomass covering the ground. We use the two schemes to investigate the interactions between vegetation, albedo and precipitation in the Sahel/Sahara for two time-slices: preindustrial and mid-Holocene. The dynamic scheme represents the seasonal cycle of albedo and the correspondence between annual mean albedo and vegetation cover in a more consistent way than the static scheme. It thus gives a better estimate of albedo change between the two time periods. With the introduction of the dynamic scheme, precipitation is increased by $30 \mathrm{~mm} \mathrm{yr}^{-1}$ for the pre-industrial simulation and by about $80 \mathrm{~mm} \mathrm{yr}^{-1}$ for the mid-Holocene simulation. The present-day dry bias in the Sahel of standard ECHAM5 is thus reduced and the sensitivity of precipitation to mid-Holocene external forcing is increased by around one third. The locations of mid-Holocene lakes, as estimated from reconstructions, lie south of the modelled desert border in both mid-Holocene simulations. The magnitude of simulated rainfall in this area is too low to fully sustain lakes, however it is captured better with the dynamic scheme. The dynamic scheme leads to increased vegetation variability in the remaining desert region, indicating a higher frequency of green spells, thus reaching a better agreement with the vegetation distribution as derived from pollen records.
\end{abstract}

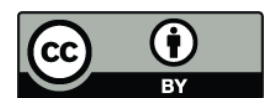

Correspondence to: F. S. E. Vamborg (freja.vamborg@zmaw.de)

\section{Introduction}

Investigating climates of the past offers an opportunity to improve our understanding of future Earth system dynamics. During the mid-Holocene, around six thousand years ago, the West African monsoon reached much further north than it does today. The area that today is covered by the Sahara was largely vegetated, as established using e.g. pollen reconstructions (e.g. Jolly et al., 1998b). The vegetation cover extended at least up to $23^{\circ} \mathrm{N}$ (Jolly et al., 1998a), if not across the whole of North Africa (Hoelzmann et al., 1998), compared to about $12^{\circ} \mathrm{N}$ today (de Noblet-Ducoudre et al., 2000). Lake abundance and lake levels also increased throughout North Africa and on the Arabian Peninsula (Hoelzmann et al., 1998).

The mechanisms responsible for the northward shift and intensification of the palaeo-monsoon and subsequent greening have been studied extensively using models, including general circulation models (GCMs). The largest differences in external forcing between the mid-Holocene and today are radiative forcing anomalies arising from changes in the Earth's orbital parameters (Berger, 1978). It is now largely accepted that the main reason for changes in the palaeomonsoon was an increased seasonal cycle of insolation in the Northern Hemisphere due to a change in these parameters (de Noblet-Ducoudre et al., 2000). However, as demonstrated by several modelling experiments, a change in just the orbital parameters is not sufficient to induce strong enough changes in the monsoon to agree with reconstructed vegetation and precipitation (Joussaume et al., 1999). In order to obtain the correct signal, several feedback mechanisms have been suggested, such as ocean amplification (e.g. Kutzbach and Liu, 1997) and vegetation-atmosphere feedbacks (e.g. Claussen and Gayler, 1997; de Noblet-Ducoudre et al., 2000). The combined effect of orbital change, ocean feedbacks and vegetation feedbacks corresponds best to palaeoreconstructions (Braconnot et al., 2007a). 

a. Static scheme
b. Tile with PFT $i$
c. Dynamic scheme
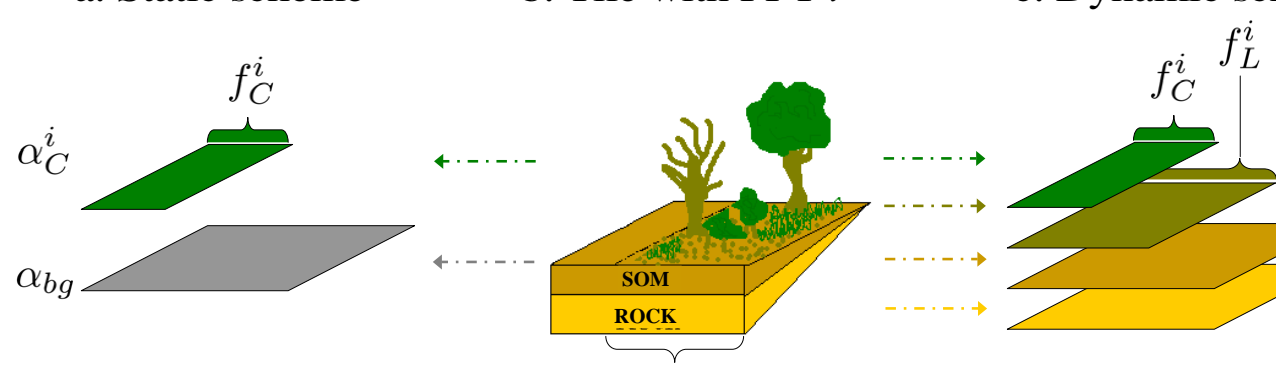

$V_{\max }$

$f_{\text {cover }}^{i}$

Fig. 1. Sketch illustrating the components needed to calculate $\alpha^{i}$, the land surface albedo of the tile containing PFT $i$ according to the static (a) and dynamic (c) background albedo schemes. Arrows and colours indicate the correspondence between albedo and a modelled tile (b). Several PFTs are depicted in this tile to illustrate the origin of the different albedo layers.

Notations are as follows:

(a) $\alpha_{\mathrm{C}}^{i}$ - canopy-albedo for PFT $i, \alpha_{\mathrm{bg}}$ - background albedo defined per gridbox, $f_{\mathrm{C}}^{i}$ - the fraction of $\alpha^{i}$ that is calculated from $\alpha_{\mathrm{C}}^{i}$

(b) SOM - organic soil layer, ROCK - mineral soil layer, $V_{\max }$ - vegetated fraction of tile, $f_{\text {cover }}^{i}$ fraction of gridbox covered by PFT $i$.

(c) $\alpha_{\mathrm{C}}^{i}, f_{\mathrm{C}}^{i}$ as in (a), $\alpha_{\mathrm{L}}^{i}-$ litter and phytomass albedo for pft $i, f_{\mathrm{L}}^{i}$ - the fraction of $\alpha_{\mathrm{bg}}^{i}$ that is calculated from $\alpha_{\mathrm{L}}^{i}$, $\alpha_{\mathrm{SOM}}-$ albedo of the gridbox bare ground, $\alpha_{\mathrm{ROCK}}-$ albedo of SOM-free bare ground, $\alpha_{\mathrm{bg}}^{i}-$ background albedo for PFT $i$.

A positive vegetation feedback in the Sahel/Sahara transition region was first proposed by Charney (1975). He suggested that areas with an elevated albedo (e.g. deserts) have a more stable air column than surrounding areas and thus precipitation is suppressed above the desert. With aridification this mechanism is extended and a positive feedback loop occurs, leading to self-stabilisation of the desert. If, reversely, vegetation growth is extended into a desert area, albedo is reduced and the mechanism works the opposite way. During the mid-Holocene, rainfall in the Sahel was increased by the insolation anomaly and this feedback could have taken place. The main driver behind Charney's theory is a change in surface albedo, but the theory ignores other vegetation-related moisture feedbacks, such as increased transpiration, which could also affect rainfall (Xue and Shukla, 1993; Brovkin et al., 1998). Nevertheless, several GCM studies have shown that surface albedo is the key variable for obtaining a positive feedback between land surface and precipitation in the Sahel/Sahara region (e.g. Claussen, 1997; Levis et al., 2004; Schurgers et al., 2007), rather than other processes. Thus, to correctly quantify the magnitude of this feedback, the landsurface albedo of both deserts and vegetated areas has to be modelled realistically.

Land surface albedo schemes in the current generation of GCMs are usually based on the following considerations (Wang et al., 2007): land surface albedo, $\alpha_{\mathrm{S}}$, is calculated as the sum of the albedo of all plant functional types (PFTs), $\alpha^{i}$, weighted by their cover fractions, $f_{\text {cover }}^{i}$ The albedo of PFT $i, \alpha^{i}$, is calculated as the weighted average of the canopy albedo of PFT $i, \alpha_{\mathrm{C}}^{i}$, and the albedo of the surface below the canopy, the background albedo $\alpha_{\text {bg }}$ (see Fig. 1). The canopy fraction of PFT $i, f_{\mathrm{C}}^{i}$, is based on the presence of green leaves, which is defined through the leaf area index (LAI). The background albedo is based on a time-invariant map, either derived from satellite data or from soil type data. In some cases the background albedo varies with soil moisture (e.g. Oleson et al., 2004; Wang, 2005), but in many schemes, e.g. in JSBACH, the land surface scheme of the Earth system model of the Max Planck Institute for Meteorology (MPIESM), it is constant. For the present-day situation the background albedo can be captured well by satellite observations and the method described above is appropriate. However, if the vegetation cover differs substantially from the one of today, for instance in the past or in possible future scenarios, this approach may be inadequate, since background albedo as well as canopy cover could change significantly within those time frames.

In arid to semiarid regions, the land surface albedo varies seasonally, with changes in LAI being one of the main modulators of these changes. During the dry season, when LAI is close to zero, the albedo is controlled partly by the albedo of bare ground and partly by the amount of litter and standing dead phytomass masking the ground (Samain et al., 2008). To capture albedo changes in the Sahel/Sahara one should thus consider, not just the LAI-cycle, but also the albedo of bare ground and the albedo of litter. The background albedo values in the Sahara are very inhomogeneous, with some areas (hot desert) having extremely high albedo values. Albedo in these areas is linked to soil formation processes such as lake dessication and salt crusting. High albedo areas in the present day act to suppress precipitation (Knorr et al., 2001; Knorr and Schnitzler, 2006). In many models these 
inhomogeneities are ignored, leading to inter-model biases in the strength and extent of the present-day West African Monsoon (WAM) (Bonfils et al., 2001). Levis et al. (2004) showed that altering the soil composition and soil colour to represent different amounts of soil organic matter (SOM) in the Sahara during the mid-Holocene also leads to a further increase in precipitation, compared to using present-day values. This increase mainly arises from a reduction in albedo. These studies highlight the importance of considering all these components dynamically to fully capture the albedo differences between the mid-Holocene and today and thus to better quantify the vegetation-precipitation feedback.

In this paper, we present a land surface albedo scheme, in which the $\alpha_{\text {bg }}$ changes in time as well as in space. We compare the effect on precipitation of two albedo schemes, the static and dynamic schemes, for the present day (preindustrial setup) and for the mid-Holocene, focusing on North Africa and the Arabian Peninsula.

\section{Dynamic background albedo scheme}

For the experiments in this paper we used the spectral atmosphere model ECHAM5 (Roeckner et al., 2003) in T31 resolution with 19 levels in the vertical coupled to the land surface scheme JSBACH extended with a dynamic vegetation module (Raddatz et al., 2007; Brovkin et al., 2009). A tiling approach is used to represent sub-gridbox vegetation dynamics. Tile $i$ is the gridbox space that is occupied by PFT $i$.

All albedo values in JSBACH are calculated separately, but according to the same equation, for the two spectral bands; visible (VIS) and near infrared (NIR). Throughout the paper, we only refer to albedo values as $\alpha_{X}^{i}$ or $\alpha_{X}$, where $i$ indicates PFT-specific values and $X$ is the type of albedo referred to (such as $S$ for surface, $C$ for canopy etc.). The dependence on the spectral bands is thus implicit in the equations and only explicitly shown for parameterisation in Table 1. The radiation scheme in ECHAM5 used in these simulations represents six bands for incoming short-wave radiation in the range $0.25-4.00 \mu \mathrm{m}$; three ultraviolet (UV) and VIS bands, and three NIR bands. The VIS and NIR albedo values calculated in JSBACH are used by ECHAM5 accordingly (the VIS albedo for the UV + VIS bands and the NIR albedo for the NIR bands). The albedo discussed in the results section is the combined mean land surface albedo calculated by ECHAM5, at each output time-step, from the VIS and NIR albedo values calculated by JSBACH.

\subsection{Standard albedo scheme in JSBACH}

For snow-free land in JSBACH the albedo of each PFT $i, \alpha^{i}$, is calculated according to:

$\alpha^{i}=f_{\mathrm{C}}^{i} \alpha_{\mathrm{C}}^{i}+\left(1-f_{\mathrm{C}}^{i}\right) \alpha_{\mathrm{bg}}$.
Table 1. Albedo values used in the dynamic albedo scheme.

\begin{tabular}{lccll}
\hline Plant functional type & $\alpha_{\mathrm{C}, \mathrm{vis}}^{i}$ & $\alpha_{\mathrm{C}, \mathrm{nir}}^{i}$ & $\alpha_{\mathrm{L}, \mathrm{vis}}^{i}$ & $\alpha_{\mathrm{L}, \mathrm{nir}}^{i}$ \\
\hline tropical broadleaf evergreen trees & 0.03 & 0.22 & 0.09 & 0.07 \\
tropical broadleaf deciduous trees & 0.04 & 0.23 & 0.1 & 0.08 \\
extra-tropical evergreen trees & 0.04 & 0.22 & 0.07 & 0.07 \\
extra-tropical deciduous trees & 0.05 & 0.25 & 0.08 & 0.1 \\
raingreen shrubs & 0.05 & 0.25 & 0.11 & 0.2 \\
deciduous shrubs & 0.05 & 0.28 & 0.11 & 0.23 \\
C3 grass & 0.08 & 0.34 & 0.14 & 0.29 \\
$\mathrm{C} 4$ grass & 0.08 & 0.34 & 0.14 & 0.29 \\
\hline
\end{tabular}

The albedo of the canopy (green leaves), $\alpha_{\mathrm{C}}^{i}$, is PFT-specific (see Table 1), whereas the background albedo $\alpha_{\mathrm{bg}}$ is defined per gridbox independent of PFTs. $\alpha_{\mathrm{bg}}$ is constant in time and read in as two maps, one for each of the spectral bands, at the beginning of each experiment. These maps have been derived from MODIS reflectance data in a manner similar to Rechid et al. (2009). The fraction of the tile for PFT $i$ that is covered by the canopy, $f_{\mathrm{C}}^{i}$ (Eq. 2), varies with the fraction of the gridbox that is vegetated $\left(V_{\max }\right)$ and with the leaf area index $\left(\mathrm{LAI}^{i}\right)$ of PFT $i$ :

$f_{\mathrm{C}}^{i}=V_{\max }\left(1-e^{-\mathrm{LAI}^{i} / 2}\right)$.

It can thus vary in space and time. Note that the stem area effect on albedo is only taken into account in snow-covered areas, and is thus not reflected here. Finally the albedo values of all PFTs are weighted by their vegetation cover fraction $f_{\text {cover }}^{i}$ and summed to a gridbox-averaged surface albedo, $\alpha_{\mathrm{S}}$ :

$\alpha_{\mathrm{S}}=\sum_{\mathrm{PFT}} f_{\text {cover }}^{i} \alpha^{i}$.

\subsection{Dynamic background albedo}

In the above version of the scheme, $\alpha_{\mathrm{bg}}$ is constant in time and defined per gridbox. We introduce a time-varying and PFT-specific background albedo $\alpha_{\mathrm{bg}}^{i}$, which replaces the $\alpha_{\mathrm{bg}}$ in Eq. (1). The standard (static) and the dynamic approach are illustrated in Fig. 1. All other albedo calculations remain the same.

There are two main factors that affect the background albedo; bare ground and the standing non-green phytomass and litter. We will discuss the dynamic scheme around these two factors. The albedos corresponding to these factors are $\alpha_{\mathrm{SOM}}$ and $\alpha_{\mathrm{L}}^{i}$. The new albedo of the background is then calculated per PFT as the weighted sum of these factors, where the weighting factor $f_{\mathrm{L}}^{i}$ represents the area of the tile covered by litter:

$\alpha_{\mathrm{bg}}^{i}=f_{\mathrm{L}}^{i} \alpha_{\mathrm{L}}^{i}+\left(1-f_{\mathrm{L}}^{i}\right) \alpha_{\mathrm{SOM}}$.

As for the surface albedo, this albedo is calculated separately for the two spectral bands VIS and NIR. 


\subsubsection{Albedo of bare ground: $\alpha_{\text {SOM }}$}

The main properties modulating the reflectance of bare ground are the different mineral components (the underlying parent material) and soil organic matter (SOM) (Ladoni et al., 2010). The relationship between SOM and reflectance is often assumed to be linear, with SOM being negatively correlated to reflectance up to a saturation limit of around 5\% SOM in the top soil layer (Curran, 1985; Ladoni et al., 2010). The maximum change in VIS and NIR reflectance due to $\operatorname{SOM}\left(a \cdot C_{\text {lim }}\right.$, in Eq. 5) is between 0.1 and 0.3 (e.g. Stoner and Baumgardner, 1981; Curran, 1985; Bartholomeus et al., 2008). Here we use a conservative estimate of 0.15 . The relationship may vary spatially, mainly due to different parent materials (Henderson et al., 1992). To capture this, we define a variable representing the albedo of the bare ground that does not contain any SOM, $\alpha_{\text {ROCK }}$. We assume, for the purpose of our study, that the time-scales are too short for major changes in soil mineral composition and $\alpha_{\mathrm{ROCK}}$ is thus constant in time in our simulations. We use the gridbox average of the modelled slow soil carbon pool $C_{\mathrm{ss}}\left(\operatorname{mol}(\mathrm{C}) \mathrm{m}_{\text {gridbox }}^{-2}\right)$ as a proxy for SOM. The slow soil carbon pool represents the carbon in the soil that mineralizes at a slow rate and it has a turnover time of 150 years. We introduce a saturation limit $C_{\text {lim }}$ beyond which increasing SOM does not affect the albedo. The value of $C_{\lim }$ was chosen on one hand to correspond to the geographical transition from low to medium amounts of soil organic carbon (SOC) in the top-soils of tropical Africa (FAO, 2007) and on the other hand to obtain reasonable estimates for $\alpha_{\text {ROCK }}$ (see below). The albedo of a bare ground surface containing SOM, $\alpha_{\mathrm{SOM}}$, is thus derived as a linear function of SOM up to the saturation limit $C_{\mathrm{lim}}$, with $\alpha_{\text {ROCK }}$ as intercept:

$\alpha_{\mathrm{SOM}}=\alpha_{\mathrm{ROCK}}-a \cdot \min \left(C_{\mathrm{ss}}, C_{\mathrm{lim}}\right)$

where $a=3 \times 10^{-4} \mathrm{~m}_{\text {gridbox }}^{2} \mathrm{~mol}^{-1}(\mathrm{C})$ and $C_{\text {lim }}=500 \mathrm{~mol}(\mathrm{C})$ $\mathrm{m}_{\text {gridbox }}^{-2}$. This calculation is done per gridbox and is not PFT specific.

Rock albedo, $\alpha_{\mathrm{ROCK}}$, should ideally be derived from bedrock or sediment properties. The standard $\alpha_{\mathrm{bg}}$ is derived from satellite data, by considering the times of the year with the lowest LAI. For the variable $\alpha_{\mathrm{ROCK}}$ it is not possible to derive the information directly from satellite data, except for desert regions. There have been attempts to correlate MODIS albedo with FAO soil maps and USGS geological maps (Tsvetsinskaya et al., 2002, 2006). These correlations are region-specific and only give data for present-day desert areas. Since we are interested in global data, this approach does not provide additional information for extracting $\alpha_{\text {ROCK }}$ compared to the MODIS-derived maps for $\alpha_{\mathrm{bg}}$ currently used in JSBACH. We derive $\alpha_{\mathrm{ROCK}}$ by assuming that for the present-day simulation $\alpha_{\mathrm{SOM}}=\alpha_{\mathrm{bg}}$ and using the inverse calculation of Eq. (5). This of course does not hold for areas where litter and phytomass cover the bare ground.
We did not include the dependence of bare ground albedo on soil moisture in this relationship, even though it is well documented that background albedo generally decreases with increasing soil moisture (e.g. Domingo et al., 2000; Lobell and Asner, 2002; Gascoin et al., 2009). This limitation is justified for two reasons: First, soil hydrology is represented by a rather crude bucket model in JSBACH of $1 \mathrm{~m}$ depth, while albedo is only affected by soil water if the upper few millimetres to centimetres of the soil are wet (Gascoin et al., 2009). This effect can thus not be included in the current version of JSBACH in an appropriate way. Second, the map used to derive the rock albedo is an annual mean and therefore neither represents completely dry nor completely wet soil, an appropriate dry albedo could thus not be derived. However, in principle, the soil moisture effect could easily be included.

\subsubsection{Albedo of non-green phytomass: $\alpha_{L}$}

Litter storage is represented for each PFT $i$ in JSBACH by two carbon pools: woody litter $W^{i}$ and leaf litter $L^{i}$ $\left(\operatorname{mol}(\mathrm{C}) \mathrm{m}_{\text {vegetated area }}^{-2}\right)$. The turnover time of the leaf litter pool depends on soil moisture and temperature and is about one and a half years. We use $L^{i}$ as a proxy for the combined amount of litter and aboveground dead phytomass in a tile. We assume that $L^{i}$ is spread equally across the vegetated part of the tile $\left(V_{\max }\right)$. Further we assume that the fraction of the tile covered by litter can be derived in a similar way to the derivation of the fraction of the tile covered by green leaves (see Eq. 2). The LAI ${ }^{i}\left(\mathrm{~m}_{\text {leaf }}^{2} \mathrm{~m}_{\text {canopy }}^{-2}\right)$ in Eq. 2 is derived by multplying the specific leaf area SLA ${ }^{i}$ (leaf area per unit mass, $\mathrm{m}_{\text {leaf }}^{2} \mathrm{~mol}^{-1}(\mathrm{C})$ ) with the mass of green leaves $\mathrm{M}^{i}\left(\operatorname{mol}(\mathrm{C}) \mathrm{m}_{\text {canopy }}^{-2}\right)$. Here we introduce a leaf area index for litter, $\operatorname{LAI}_{\mathrm{L}}^{i}\left(\mathrm{~m}_{\text {leaf }}^{2} \mathrm{~m}_{\text {vegetated area }}^{-2}\right)$, derived by multiplying $L^{i}$ with $\mathrm{SLA}^{i}$ :

$\mathrm{LAI}_{\mathrm{L}}^{i}=\operatorname{SLA}^{i} L^{i}$.

For the canopy, the factor of 0.5 in the exponent represents the non-ordering of leaves, i.e. that leaves hang at different angles and thus do not cover the ground with maximum area. For litter it would be possible that all leaves align, in which case this factor underestimates the actual coverage by litter. Litter is however freer to move than leaves in the canopy, which means that it could be subjected to clumping, in which case this factor would over-estimate the area covered by litter. Since we lack data on which of these effects is stronger, we keep this factor at 0.5 for the litter equation. The fraction of the tile that is covered by litter is thus calculated as follows:

$f_{\mathrm{L}}^{i}=V_{\max }\left(1-e^{-\mathrm{LAI}_{\mathrm{L}}^{i} / 2}\right)$

To derive the albedo values for litter, $\alpha_{L}^{i}$, we grouped the PFTs into two larger groups, the first representing trees and the second shrubs and grasses, and assumed that the change 
Table 2. Experimental setup. Experiment: analysed (bold), Component: AV = echam5-jsbach, $-\mathrm{O}=$ coupled to MPIOM, Veg: prescribed (-) or dynamic (dyn) vegetation, Albedo: static (-) or dynamic (dyn) albedo scheme, Init veg: run from which initial or prescribed vegetation was taken, Cpool: run from which forcing for carbon offline model (used to initialise carbon pools) was derived, SST: run from which SST and SIC were derived, Orbit: $0 \mathrm{~K}$ or $6 \mathrm{~K}$ orbital forcing, Years: length of run in years.

\begin{tabular}{llllllllr}
\hline Experiment & Component & Veg & Albedo & Init veg & Cpool & SST & Orbit & Years \\
\hline OK_ctrl & AV-O & dyn & - & - & - & - & $0 \mathrm{~K}$ & $>4500$ \\
0K & AV & - & - & 0K_ctrl & - & 0K_ctrl & $0 \mathrm{~K}$ & 200 \\
0K_st & AV & dyn & - & 0K_ctrl & 0K & 0K_ctrl & 0K & 300 \\
0K_dyn & AV & dyn & dyn & 0K_ctrl & 0K,0K_dyn & 0K_ctrl & 0K & $100+300$ \\
\hline 6K_ctrl & AV-O & dyn & - & - & - & - & $6 \mathrm{~K}$ & $>4500$ \\
6K & AV & - & - & 6K_ctrl & - & 6K_ctrl & $6 \mathrm{~K}$ & 200 \\
6K_st & AV & dyn & - & 6K_ctrl & 6K & 6K_ctrl & $6 \mathrm{~K}$ & 300 \\
6K_dyn & AV & dyn & dyn & 6K_ctrl & 6K, 6K_dyn & 6K_ctrl & $6 \mathrm{~K}$ & $100+300$ \\
\hline
\end{tabular}

from canopy to litter albedo was the same within the groups. We used the values for live and dead leaves in Sellers et al. (1996) as guidance for the direction of change. The general pattern is that dead leaves have a higher reflectivity in the visible spectrum than green leaves, in the near infrared the tendency is rather the opposite, although this is not always the case (Asner et al., 1998). The MODIS maps for $\alpha_{\mathrm{bg}}$ are the best approximation that we have for the background albedo. We calculated a new gridbox average albedo, $\alpha_{\mathrm{bg}}^{\mathrm{dyn}}$, using the new scheme:

$\alpha_{\mathrm{bg}}^{\mathrm{dyn}}=\sum_{\mathrm{PFT}} f_{\text {cover }}^{i} \alpha_{\mathrm{bg}}^{i}$

The carbon pools needed for this calculation were taken from a pre-industrial control simulation with fixed vegetation and static background albedo scheme (exp. 0K in Table 2). By assuming that $\alpha_{\text {dyn }}^{\mathrm{bg}}$ should fit $\alpha_{\mathrm{bg}}$ as closely as possible, we adjusted the litter albedo values to arrive at the final parameterisation (see Table 1). In the VIS we subdivided the tree group into extra-tropical and tropical trees to obtain a better fit.

\section{Experimental design}

The main purpose of the dynamic background albedo scheme is to investigate the interaction between the land surface and precipitation in the mid-Holocene Sahara. We focus on the interactions between the land and the atmosphere, which means that it is sufficient to run the model with only atmospheric components, forced with sea surface temperatures (SSTs) and sea ice cover (SIC). To capture interannual variability in the SSTs, we use 100 years of monthly mean SSTs and SIC from two coupled atmosphere-ocean simulations with the MPI-ESM that only differ in the orbital forcing, one for pre-industrial and one for the mid-Holocene, as described in Fischer and Jungclaus (2010). Since the dynamic background albedo scheme depends on the carbon pools, the carbon model has to be run into equilibrium. The simulations with dynamic background albedo were first integrated for 100 years to produce a preliminary climatology. This climatology was used as forcing for the JSBACH carbon model until equilibrium was reached. The carbon pools thus obtained were used to re-initialise the ECHAM5-JSBACH simulations, which were run until a reasonable equilibrium in the vegetation distribution and the carbon pools was reached.

The experiments were performed with either: (1) Orbitaland SST-forcing for pre-industrial or mid-Holocene and (2) static or dynamic background albedo (see Table 2). We focussed our analysis on four of these simulations: 0K_st (pre-industrial, static), 6K_st (mid-Holocene, static), 0K_dyn (pre-industrial, dynamic), 6K_dyn (mid-Holocene, dynamic). Dynamic vegetation was used in all simulations. We used the last 100 years of each multi-century simulation (see "Years" in Table 2) as analysis period. We focussed on the region $10^{\circ} \mathrm{W}-50^{\circ} \mathrm{E}, 10^{\circ} \mathrm{N}-32^{\circ} \mathrm{N}$, subdivided zonally in: WS - Western Sahara, $10^{\circ} \mathrm{W}-10^{\circ} \mathrm{E}, \mathrm{ES}$ - Eastern Sahara, $10^{\circ} \mathrm{E}-30^{\circ} \mathrm{E}$, and AP - the Red Sea and the Arabian Peninsula, $30^{\circ} \mathrm{E}-50^{\circ} \mathrm{E}$. We refer to the scheme presented in this paper as the dynamic scheme and the static scheme for the standard version in JSBACH. The terms pre-industrial and mid-Holocene simulations refer to the two sets of simulations for each time-slice (0K_st and 0K_dyn resp. 6K_st and $6 K_{-}$dyn).

\section{Results}

\subsection{Mean changes in albedo, precipitation and desert fraction}

The observed annual mean land-surface albedo in north Africa has a distinct meridional geographical pattern, with an abrupt transition from low albedo values in the south (ca. 0.2), progressively increasing through the Sahel, culminating in high to very high albedo values $(0.35-0.5)$ in the 

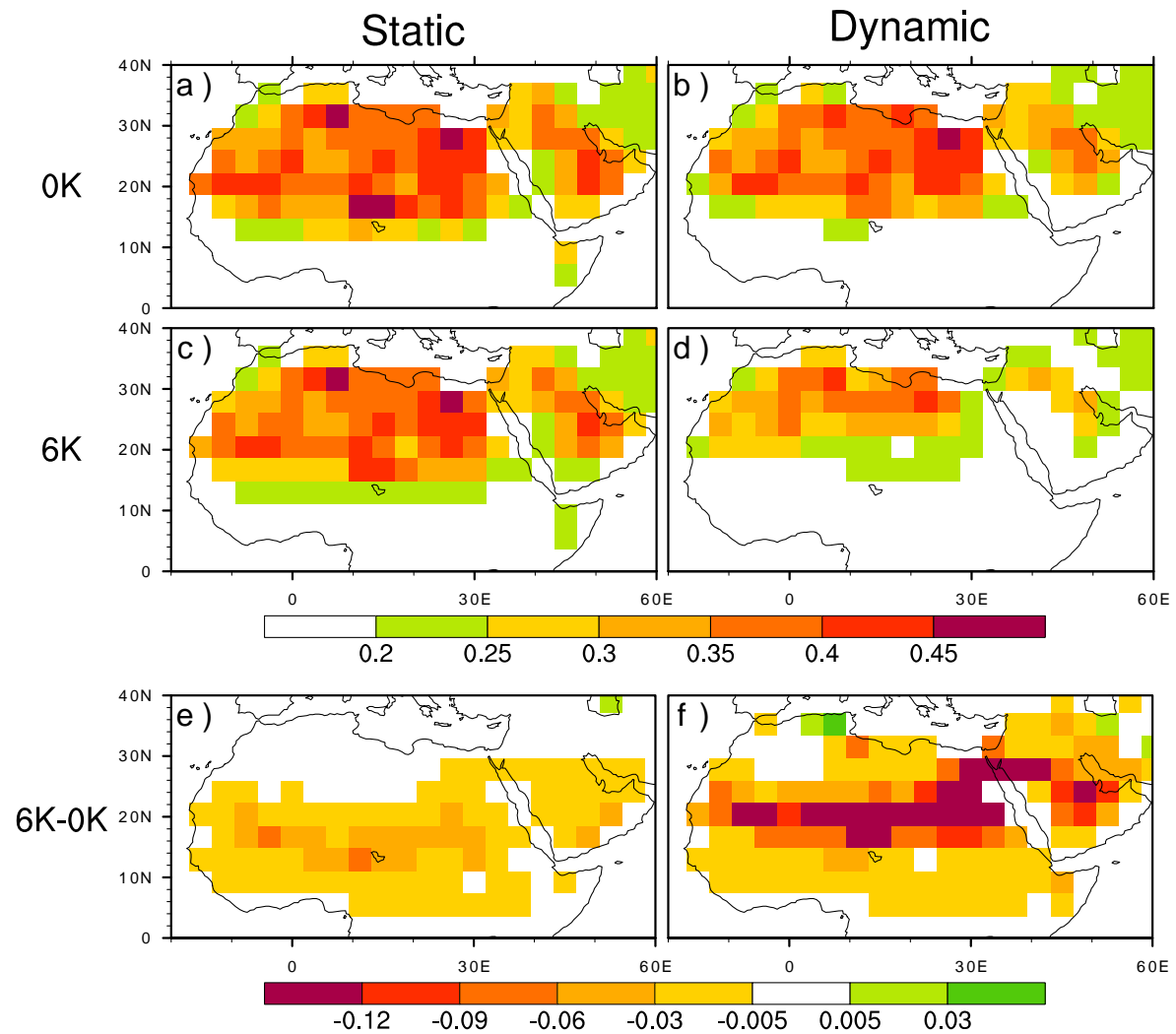

Fig. 2. Land surface albedo $\alpha_{S}$ averaged over 100 years for (a) 0K_st, (b) 0K_dyn, (c) 6K_st, (d) 6K_dyn. 100-year mean land surface albedo differences between (e) 6K_st and 0K_st, (f) 6K_dyn and 0K_dyn.

Sahara within some four degrees latitude (e.g. Rechid et al., 2009). This pattern is closely linked to the vegetation cover, from fully covered in the south to sparse and no cover in the north (Tucker and Nicholson, 1999). The transition in albedo is also clearly seen in the dry-season albedo and thus does not only arise from varying amounts of canopy cover (Samain et al., 2008).

We use the model-simulated variable desert fraction as a measure for vegetation in the simulations. The desert fraction is the fraction of a gridbox that has been completely non-vegetated for 50 years. The remaining part of the gridbox may display intermittent bare ground behaviour. In 0K_st, the desert border (the border of 0.5 desert fraction) is at around $14^{\circ} \mathrm{N}$ (Fig. 3a), which corresponds well to the present-day Sahel/Sahara border (Tucker and Nicholson, 1999). As in observations, the fast transition from low to high albedo values coincides with the desert border and the gridboxes with very high albedo values (above 0.35 ) all lie north of the desert border (Fig. 2a). The general correspondence between vegetation cover and albedo seen in the annual mean observations is thus well represented in $0 \mathrm{~K} \_s t$.

In 0K_dyn, the albedo (Fig. 2b) remains close to that of 0K_st, except across the Sahel, from around $10^{\circ} \mathrm{N}$ to $18^{\circ} \mathrm{N}$, where the albedo is reduced by around 0.06 . The transition from low to high albedo values, though shifted sligthly northward, still agrees well with observations (e.g. Knorr et al., 2001) and as with the static scheme, the vegetation cover and albedo correspondence is captured well (Fig. 3b). The reduction in albedo in the Sahel leads to a local intensification of precipitation across the region of about $30 \mathrm{~mm} \mathrm{yr}^{-1}$ (Fig. 4e). The observed regional annual mean precipitation is almost twice as large as the precipitation in 0K_st (19062006, CRU TS 30.5 (land); Mitchell and Jones, 2005) and the modelled $200 \mathrm{~mm} / \mathrm{yr}^{-1}$ isoline (Fig. 4a) is some degrees too far to the south (Fink et al., 2010). The introduction of the dynamic scheme thus reduces the dry bias in the Sahel that is apparent in 0K_st (standard ECHAM5).

It has previously been shown that the parameterisation of hot desert albedo controls the northward extent of the monsoon (Bonfils et al., 2001; Knorr et al., 2001; Knorr and Schnitzler, 2006). With the dynamic scheme, most of the hot desert gridboxes persist and the albedo is reduced mainly in areas where the albedo values with the static scheme are relatively low as well. This indicates that it is not just the extent of rainfall that is controlled by the albedo, but that the annual mean albedo in the Sahel controls the intensity of the annual mean precipitation for time-scales above decadal.

In 6K_st, the desert border is shifted northward by some four degrees, both in the Sahel/Sahara and on the Arabian Peninsula (Fig. 3c). The albedo differences are very small 

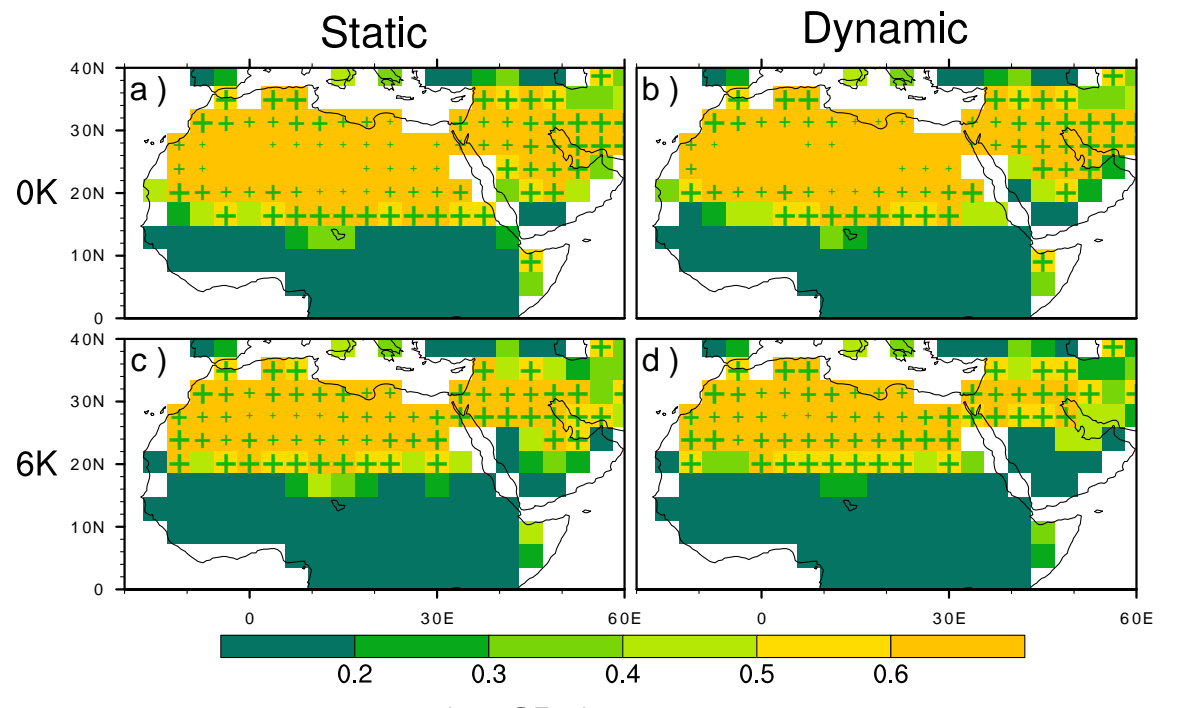

Where mean $\mathrm{DF}>0.5++++$ indicate $\mathrm{DF}$ is below $0.7,0.8,0.9$ or 0.99 at least once in 100 years

\section{Dynamic-Static}

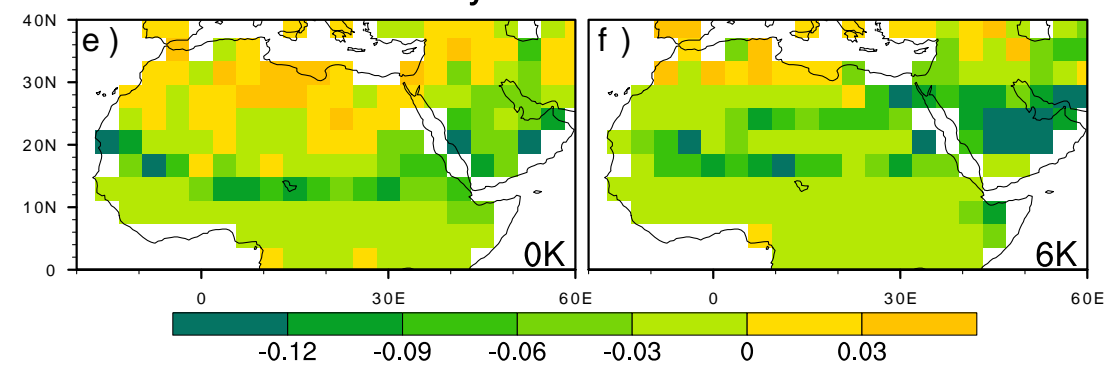

Fig. 3. Desert fraction (DF) averaged over 100 years for (a) 0K_st, (b) 0K_dyn, (c) 6K_st, (d) 6K_dyn. 100-year mean desert fraction differences between (e) 0K_dyn and 0K_st, (f) 6K_dyn and 6K_st.

between 0K_st and 6K_st (Fig. 2e). Since gridboxes in the newly vegetated areas have desert-like albedo values, the correspondence between vegetation cover and albedo, particularly at the desert border, is not apparent in this simulation (6K_st). This geographical correspondence between modelled vegetation and albedo is captured much better in the dynamic simulation 6K_dyn (Figs. 3d, 2d). Since the correspondence between vegetation cover and albedo is captured well with the dynamic scheme for both the pre-industrial and the mid-Holocene, we expect the albedo change between the two times-slices to be more realistic with the dynamic scheme than with the static scheme (Fig. $2 \mathrm{f}$ vs. e).

The lower albedo in the mid-Holocene simulation $6 \mathrm{~K} \_$dyn leads to an increase in precipitation of $80 \mathrm{~mm} \mathrm{yr}^{-1}$ in the studied region compared to 6K_st (Table 3 ). The sensitivity of precipitation to mid-Holocene orbital and SST forcings is thus increased by over a third through the introduction of the dynamic scheme.

\subsection{Spatial variability of albedo and precipitation}

To investigate spatial variability in more detail we consider zonal means over land for WS, ES and AP (Fig. 5a-c respectively and Table 3). As discussed in the previous section, the dynamic scheme increases precipitation in the pre-industrial simulation. However, the desert borders in WS and ES are barely affected and the largest changes in precipitation occur around or south of this border, showing that the dynamic scheme does not shift the rainfall substantially northwards into the Sahara. In AP the change in precipitation is smoother and stretched over a larger latitudinal band, which results in a northward shift of the desert border. The albedo change introduced by the dynamic scheme peaks south of or around the desert border in all the regions.

In the mid-Holocene static simulation (6K_st), the desert border is shifted northwards by some four degrees in WS and ES and by almost six degrees in AP. This leads to a slight reduction in albedo compared to the pre-industrial simulation (6K_st-0K_st). This reduction is at most as large as the reduction seen between the pre-industrial simulations 

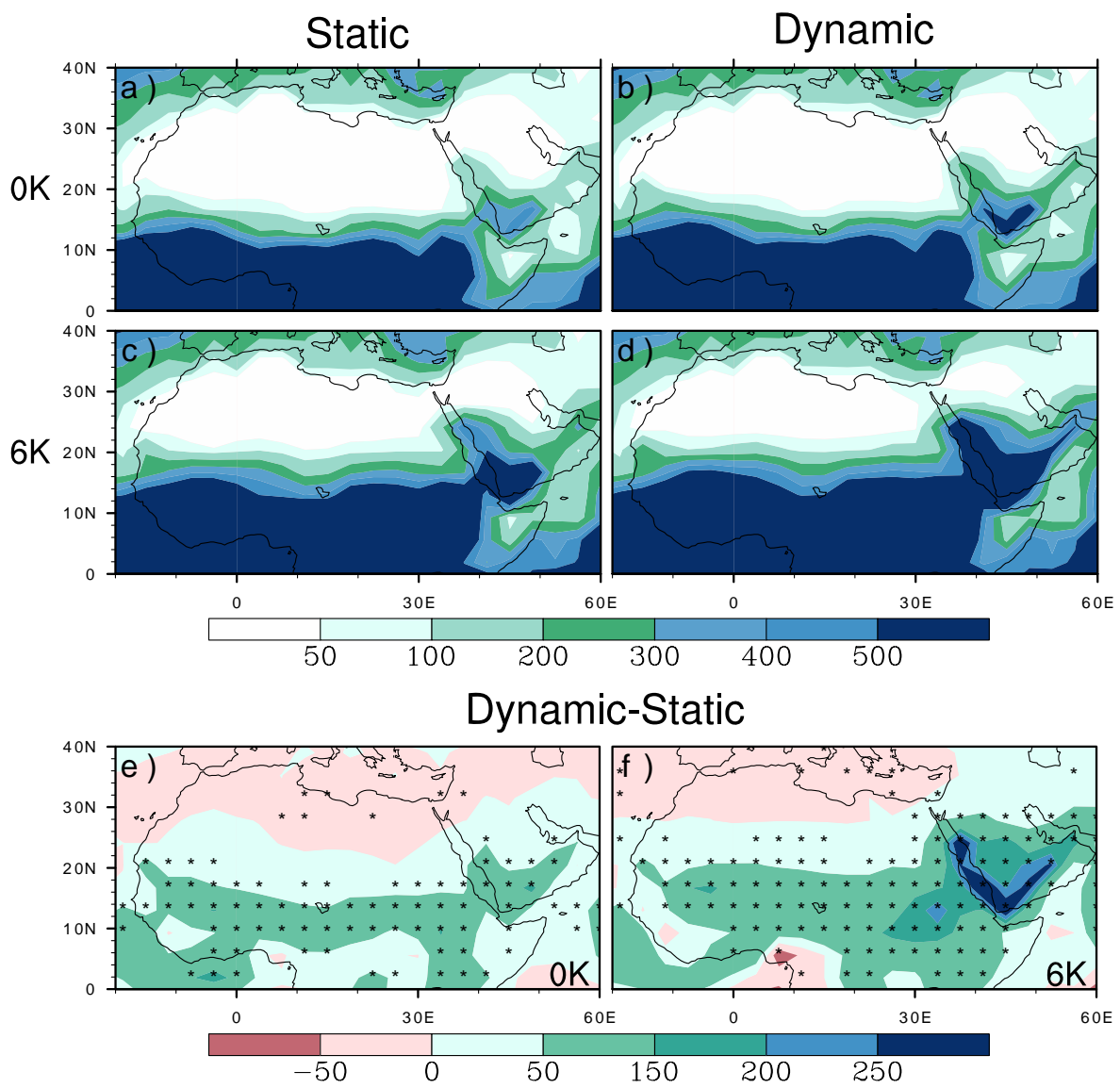

Fig. 4. Precipitation (mm year ${ }^{-1}$ ) averaged over 100 years for (a) 0K_st, (b) 0K_dyn, (c) 6K_st, (d) 6K_dyn. Differences in annual mean precipitation between (e) 0K_dyn and 0K_st, (f) 6K_dyn and 6K_st, gridbox differences significant (Student's T-test) at the 95\% level are marked with an asterix.

(0K_dyn-0K_st). Even so, the difference in precipitation between the static simulations is at many latitudes more than twice as large as the one between the pre-industrial simulations. It is thus clear that the orbital and SST forcings play an important role in the northward extent and the intensification of precipitation during the mid-Holocene. This is in line with many other studies (e.g. Braconnot et al., 2007b), but not in line with a previous study using ECHAM, where albedo forcing was a stronger driver for a northward migration of the intertropical convergence zone (ITCZ) than orbital and SST forcings (Knorr and Schnitzler, 2006).

The different response of the regions is most apparent when comparing the differences between pre-industrial and mid-Holocene simulations for both schemes (red resp. yellow lines in Fig. 5). In WS the precipitation difference between the two static simulations is negative south of $8^{\circ} \mathrm{N}$, and positive between $8^{\circ} \mathrm{N}$ and $25^{\circ} \mathrm{N}$. We can thus infer that precipitation is simultaneously increased and shifted northward. The dynamic scheme intensifies both the positive and the negative anomalies seen in the static case, showing that, in the zonal mean, the rain belt is shifted even further north by the dynamic scheme. This shift is relatively small and negligibly affects the desert border. A reason for this might be the inhibiting mechanism proposed by Knorr et al. (2001) for the present-day, since many high-albedo gridboxes persist north of the desert border even with the introduction of the dynamic scheme.

In ES, both the static and dynamic differences show a precipitation increase that is spread evenly across all latitudes. There is no reduction in rainfall to the south as seen in WS, neither for the static nor for the dynamic scheme. The dynamic scheme introduces large albedo differences across the whole desert region, even though the desert border barely shifts northwards. High albedo values can thus not be the reason for the lack of northward shift of rainfall, as they may be in WS.

The mid-Holocene response to the increased albedo forcing due to the dynamic scheme is strongest in AP. South of $20^{\circ} \mathrm{N}$, the response is similar to that of the other regions, with the dynamic scheme additionally increasing the response by one third or below. North of $20^{\circ} \mathrm{N}$, the dynamic scheme increases the precipitation by almost $100 \%$ and this occurs 
Table 3. 100-year mean albedo, precipitation $\left(\mathrm{mm} \mathrm{year}^{-1}\right)$ and desert fraction for the three areas WS, ES and AP.

\begin{tabular}{|c|c|c|c|c|}
\hline Experiment & WS & ES & $\mathrm{AP}$ & Total \\
\hline \multicolumn{5}{|c|}{ Albedo } \\
\hline OK_st & 0.34 & 0.36 & 0.26 & 0.32 \\
\hline 6K_st & 0.32 & 0.34 & 0.24 & 0.30 \\
\hline 0K_dyn & 0.31 & 0.33 & 0.23 & 0.29 \\
\hline 6K_dyn & 0.26 & 0.25 & 0.17 & 0.23 \\
\hline $6 \mathrm{~K} \_s t-0 \mathrm{~K} \_s \mathrm{st}^{1}$ & -0.02 & -0.02 & -0.01 & -0.02 \\
\hline $6 \mathrm{~K} \_$dyn-0K_dyn ${ }^{2}$ & -0.05 & -0.08 & -0.06 & -0.06 \\
\hline \multicolumn{5}{|c|}{ Precipitation $\left(\mathrm{mm}\right.$ year $\left.{ }^{-1}\right)$} \\
\hline 0K_st & $86( \pm 37)^{*}$ & $58( \pm 36)$ & $114( \pm 83)$ & $90( \pm 55)$ \\
\hline 6K_st & $195( \pm 39)$ & $167( \pm 47)$ & $261( \pm 99)$ & $217( \pm 62)$ \\
\hline OK_dyn & $115( \pm 40)$ & $77( \pm 39)$ & $152( \pm 87)$ & $119( \pm 57)$ \\
\hline 6K_dyn & $247( \pm 40)$ & $214( \pm 44)$ & $382( \pm 102)$ & $295( \pm 57)$ \\
\hline $6 \mathrm{~K} \_s t-0 \mathrm{~K} \_s t^{1}$ & 109 & 109 & 147 & 128 \\
\hline $6 \mathrm{~K} \_$dyn-0K_dyn ${ }^{2}$ & 131 & 137 & 230 & 175 \\
\hline \multicolumn{5}{|c|}{ Desert fraction } \\
\hline 0K_st & 0.70 & 0.75 & 0.62 & 0.69 \\
\hline 6K_st & 0.53 & 0.53 & 0.41 & 0.49 \\
\hline 0K_dyn & 0.69 & 0.74 & 0.57 & 0.67 \\
\hline 6K_dyn & 0.49 & 0.50 & 0.33 & 0.45 \\
\hline $6 \mathrm{~K} \_s t-0 \mathrm{~K} \_s t^{1}$ & -0.17 & -0.21 & -0.21 & -0.20 \\
\hline $6 \mathrm{~K} \_$dyn- $0 \mathrm{~K} \_$dyn ${ }^{2}$ & -0.19 & -0.24 & -0.24 & -0.23 \\
\hline
\end{tabular}

1,2 Differences in mean between 6K_st and 0K_st resp. between 6K_dyn and 0K_dyn.

* Standard deviations in precipitation calculated from 100-year climatology for each area.

even though the absolute albedo anomalies are smaller in this region than they are in the other two.

The dynamic scheme thus shifts the most sensitive region eastward compared to the static scheme. A large response across the Red Sea and the Arabian Peninsula was also found by Levis et al. (2004) when prescribing the albedo of loamlike soil in the Sahara. Here we show that this response is not just the result of imposing an uncertain but plausible boundary condition, but that it is possible to dynamically simulate this response.

\subsection{Seasonal changes in precipitation and albedo}

Precipitation in North Africa is seasonal and mainly occurs during the summer months, approximately between June and September. For a forcing mechanism to have a large impact on precipitation it would thus need to occur within or closely before the rainy season (Braconnot et al., 2008). We therefore analyse the rainfall anomalies in more detail by considering the daily means of an average year. We use running means of 15 days to reduce noise in the differences between the static and dynamic simulations and of 30 days to reduce calendar-related problems (Joussaume and Braconnot, 1997) in the differences between the pre-industrial and midHolocene simulations.

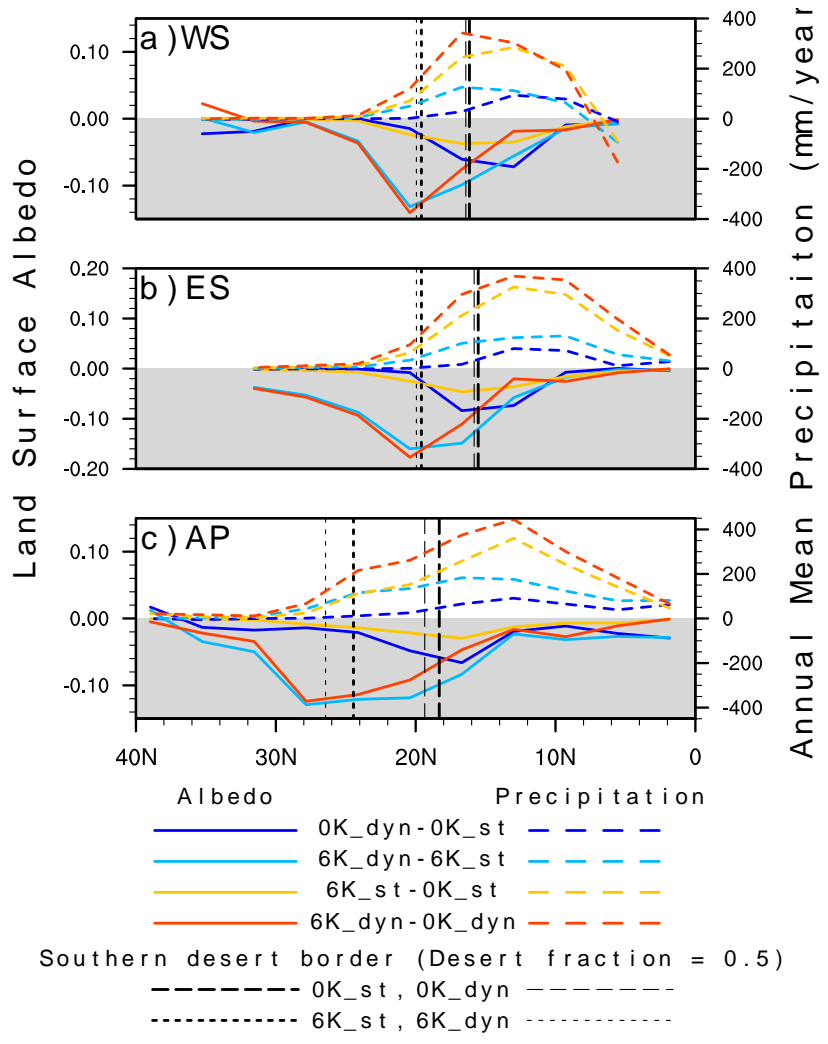

Fig. 5. Change in precipitation (mm year ${ }^{-1}$ ) and albedo averaged zonally over land and over 100 years for the regions (a) WS, (b) ES and (c) AP.

For the pre-industrial simulations the introduction of the dynamic scheme leads to anomalies of around 0.25 to $0.75 \mathrm{~mm} \mathrm{day}^{-1}$ (Fig. 6a-c) that are evenly spread across the rainy season (indicated by the overlayed contours) for all three regions. Since the rainy season is longer in WS than in ES, the absolute change is larger. The difference between the seasonal cycles of albedo for the two schemes (not shown) is almost constant throughout the year. The dynamic scheme thus does not affect the seasonality of neither albedo nor precipitation.

During the mid-Holocene (Fig. 6d-f) the positive precipitation anomalies are not limited to the 0.25 contour of the static simulation, indicating that the dynamic scheme prolongs the rainy season in all regions. In WS there is a large increase in precipitation at the beginning of the rainy season, whereas in the later part of the rainy season the anomalies are of the same order of magnitude as for the pre-industrial simulations. A drying south of $10^{\circ} \mathrm{N}$ occurs mid-season, and cancels out the increase at the beginning, which explains the northward shift of the rain belt noted in Sect. 4.2. In WS the dynamic scheme also mainly affects the beginning of the rainy season, but there is no accompanying drying to the south. In AP there is a clear intensification of rainfall throughout the rainy season. 
WS
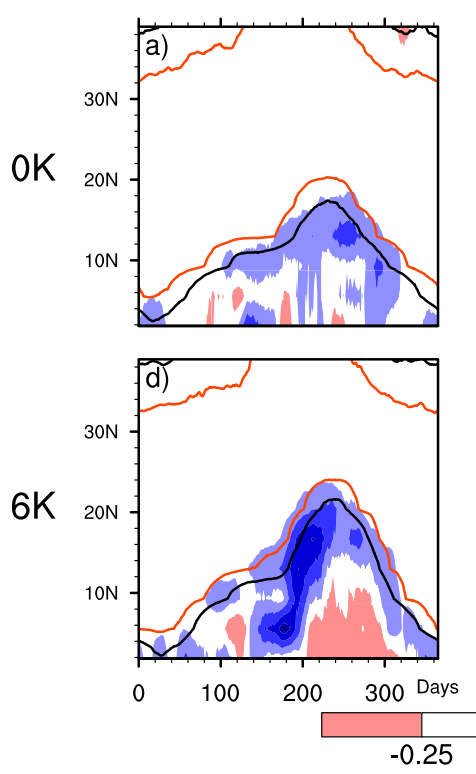

ES Dynamic-Static

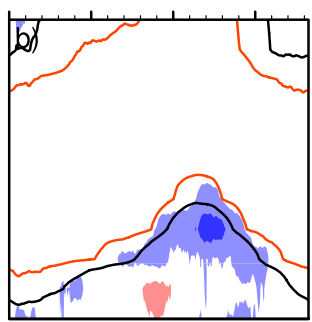

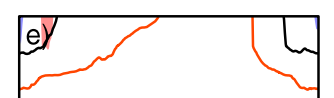

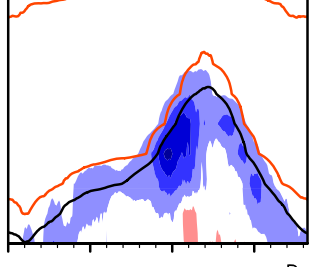

$0 \quad 100 \quad 200 \quad 300$ Days
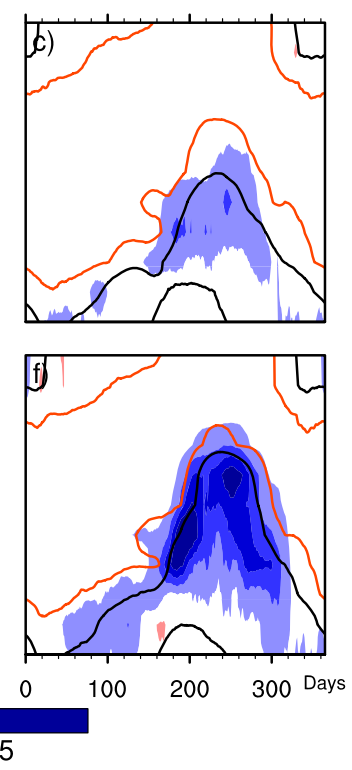

Fig. 6. Shown are differences in the annual cycle of precipitation in $\mathrm{mm} \mathrm{day}^{-1}$ derived from 100 simulation years (further filtered by 15 -day running means) for the regions WS, ES and AP between 0K_dyn and 0K_st - (a) to (c) and between 6K_dyn and 6K_st - (d) to (f). Overlayed are red and black contours representing the 0.25 and $1.25 \mathrm{~mm}$ day $^{-1}$ isolines for 0K_st - (a) to (c) and $6 \mathrm{~K}_{-}$st - (d) to (f).

These differences are also reflected in the albedo differences for the three regions (Fig. 7a-c). In WS and ES the seasonal cycle of albedo clearly changes, whereas the albedo change in AP is constant across the year. The change in albedo seasonality thus clearly matches the changed seasonality in precipitation (Fig. 6d-f), however one would need additional simulations to establish any lead-lag relationships.

Due to the extremely high background albedo values in 6K_st, the amplitude of the seasonal cycle is overestimated compared to similarly vegetated gridboxes in 0K_st (not shown). With the introduction of the dynamic scheme the seasonal cycle in albedo becomes more consistent, since comparably vegetated gridboxes also display similar albedo seasonal cycles. We thus expect the dynamic scheme to represent the seasonal distribution of rainfall in the midHolocene in a more consistent way than the static scheme.

When considering the combined effect of orbital, SST and dynamic albedo forcings (Fig. 7d-f), the differences between the pre-industrial and mid-Holocene simulations are most marked between WS and the two other regions. In the WS the northward shift of the monsoon rain belt can be seen, so that the area that has a bipolar structure in seasonal rainfall is extending further north in the mid-Holocene than in the pre-industrial simulations. In ES and AP there is a tendency towards larger increases at the end of the season. We have shown above, that the dynamic albedo scheme mainly affects rainfall at the beginning of or throughout the rainy season.
The large increase at the end of the season that we see here, must thus mainly be due to the orbital and SST forcings.

\section{Discussion}

In this section we will focus on the agreement between palaeo-records and our modelling results for the midHolocene and discuss possible ways of reducing discrepancies. According to reconstructions by Hoelzmann et al. (1998) the location of the largest increase in lake abundance was south of $20^{\circ} \mathrm{N}$ in the Sahara and along the East Coast of the Arabian Peninsula. The mid-Holocene lakes in eastern Sahara would have needed between $350-500 \mathrm{~mm}$ of precipitation a year, sometimes up to $700 \mathrm{~mm} \mathrm{yr}^{-1}$, to be sustained (Hoelzmann et al., 2000). Assuming this to hold for the entire region analysed, the amount of rainfall is underestimated in both mid-Holocene simulations. However, the simulated mid-Holocene desert border is far enough north to match the $20^{\circ} \mathrm{N}$ estimate. Annual P-E values in $6 \mathrm{~K}$ _dyn are on average $50 \%$ larger compared to $6 \mathrm{~K}$ _st, showing an increased potential for the existence of lakes. Note that the two pre-industrial simulations have similar annual P-E values, indicating that a P-E bias that could be transferred from the pre-industrial dynamic simulation to the mid-Holocene simulation is unlikely.

The Sahara was clearly reduced in the mid-Holocene compared to today (Jolly et al., 1998b). However, it is not clear if 


\section{WS $\quad$ ES AP}
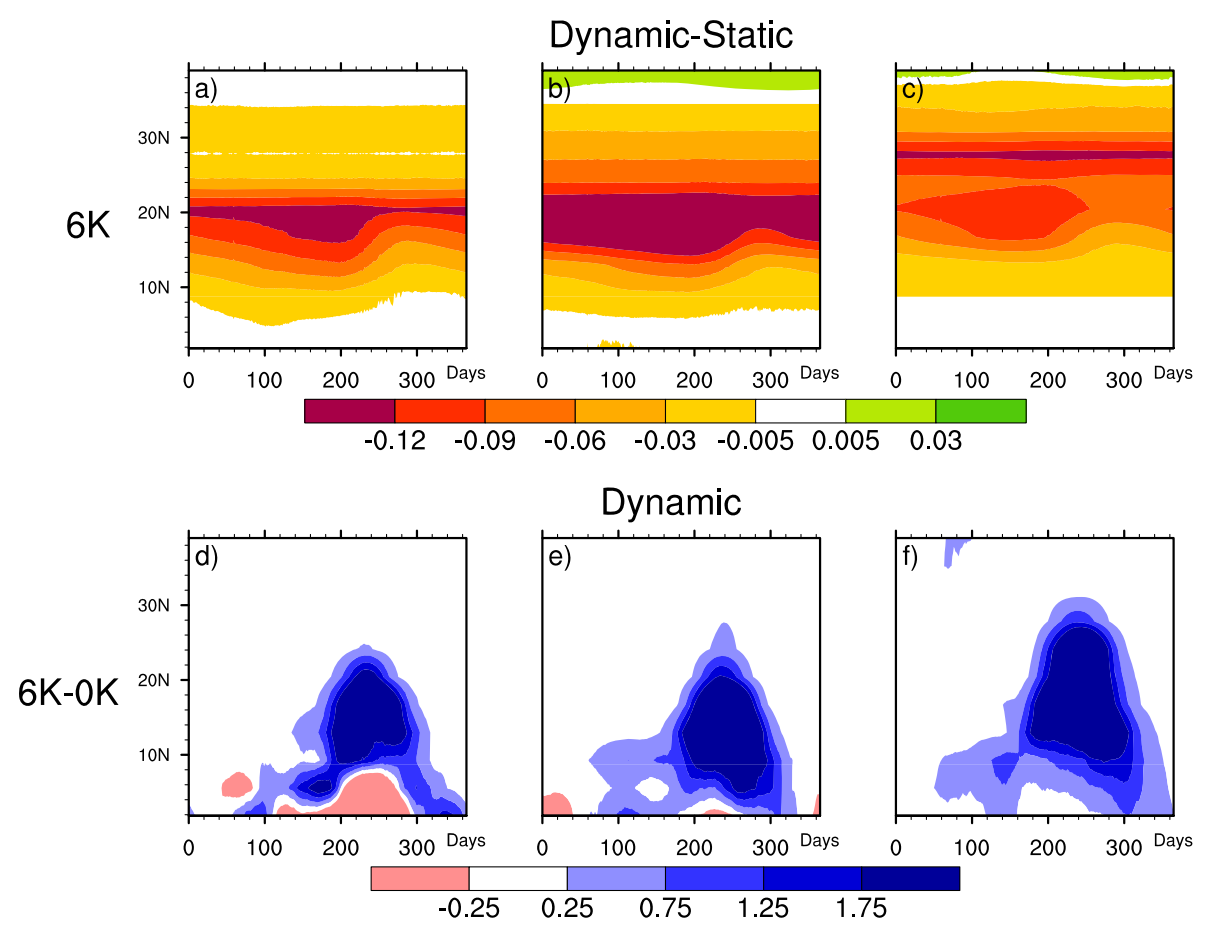

Fig. 7. Shown are differences in the annual cycle of precipitation and albedo derived from 100 simulation years. (a) to (c) show albedo differences between 6K_dyn and 6K_st, for regions WS, ES and AP. (d) to (f) show precipitation differences in $\mathrm{mm}^{-1 a y}{ }^{-1}$ (further filtered by 30 -day running means) between $6 K_{-}$dyn and 0K_dyn, for regions WS, ES and AP.

the increase in vegetation cover was restricted to favourable locations or was wide-spread as suggested by Hoelzmann et al. (1998). If there was a long-term continuous cover, one would need a very low modelled desert fraction for a close agreement between modelled values and the palaeorecord. If the pollen stem from less long-lived or patchy vegetation cover, the variability of the desert and thus its stability should be considered. As already shown, mean vegetation cover only reaches four degrees further north in the midHolocene simulations compared to the pre-industrial simulations. Our model results are thus clearly not consistent with a long-term continuously vegetated Sahara. However, we did consider the stability of the desert by studying the minimum annual mean values obtained during the 100-year analysis period (+ signs in Fig. 3a-d). One can interpret the size of these + signs as indicators of the frequency of growth events or green spells. In the pre-industrial simulations there is a large number of gridboxes where the desert fraction stays above $99 \%$ for all years, 16 boxes for 0K_dyn vs. nine for $0 K_{-}$st. The desert state is thus a very stable one. In the midHolocene simulations these very dry conditions completely disappear. 6K_dyn shows a higher frequency of green spells than its static counterpart $6 \mathrm{~K}_{-}$st, indicating a mid-Holocene Saharan climate that is more compatible with finding pollen remnants.
To match the precipitation estimates needed to sustain lakes, the increase in rainfall in our simulations seems to reach far enough north, but precipitation would need to be increased locally. There are some factors that affect the land surface albedo in the Sahel/Sahara that we have not included that may influence our results. The most important are soil moisture, fire effects (Govaerts et al., 2002; Myhre et al., 2005) and lakes and wetlands that all have the effect of reducing albedo. Fires disturbing the biosphere contributes largely to albedo variability over Africa, however the vast majority of these fires can be attributed to anthropogenic influence (see Govaerts et al., 2002, for instance) and might have been of lesser importance during the mid-Holocene. Fires affect the albedo by burnt scars on the surface, but also through their aerosol radiative effect (Govaerts et al., 2002; Myhre et al., 2005). Broström et al. (1998) found that including effects of wetlands and lakes increases the magnitude of the monsoon precipitation in the area around the prescribed lakes, but does not contribute to extending the monsoon further northward. Introducing lakes or wetlands does not only reduce the albedo, but it could also have the effect of enhancing local recycling by increasing evaporation, resulting in an increase in precipitation. This latter effect may have been important to help maintain the reconstructed palaeo lakes and wetlands (Carrington et al., 2001). One should keep in mind 
that our scheme produces a low albedo in the pre-industrial simulation that may bias the mid-Holocene simulation. Introducing further albedo-reducing mechanisms may thus push the scheme towards unrealistically low albedo values for the mid-Holocene. Thus, in order to obtain a closer agreement with lake estimates, it may be more important to introduce lakes and wetlands and their evaporative effect, rather than to further extend the albedo scheme.

We find that the vegetation effect on precipitation is almost non-existent without the dynamic scheme, which is similar to the results of e.g. PMIP2 (Braconnot et al., 2007b). However, we would argue that the albedo change is underestimated with the static scheme. Since other GCMs use schemes very similar to the static scheme, we would assume that the albedo change, and thus the vegetation-precipitaton feedback, is underestimated there as well. On the other hand, other studies that find a very strong effect of vegetation on precipitation may have overestimated the change in albedo. This overestimation could for instance arise from a bias introduced by the changed boundary conditions, such as prescribing low albedo values to the background even though the simulated precipitation increase would theoretically not lead to lower albedo values (e.g. Knorr and Schnitzler, 2006) or from overestimating the effect of the vegetation on albedo, by e.g. using a too high fixed annual mean LAI as a basis for the albedo calculation (e.g. Claussen, 1997).

Bonfils et al. (2001) found that most of the increased rainfall in the mid-Holocene was due to an increased number of extreme events. We have not gone into the details of extreme events in the analysis of our simulations. However, we find that the already low temporal variability of land surface albedo in the area is reduced by the introduction of the dynamic scheme, going from a standard deviation of around 0.004 to 0.002 (Table 3). This is also mirrored by a reduced temporal variability in rainfall. This may indicate that the occurrence of extreme events is reduced. It has been hypothesised that squall lines, today playing an important role in heavy precipitation events in the Sahel (Peters and Tetzlaff, 1988), might also have played an important role in the wetter state of the Sahara during the mid-Holocene (Pachur and Altmann, 1997). Squall lines can become very long, but their width is typically in the order of tens of kilometres, well below the scales resolved in our model simulations of T31 resolution (about $300 \mathrm{~km}$ ). Increasing resolution would be a step towards better representing heavy rainfall events in the Sahel. The combination of the dynamic scheme and higher resolution might then result in a higher mean precipitation with a large variability, which would also give rise to a higher frequency of green spells in the Sahara during the mid-Holocene.

\section{Conclusions}

We have implemented a new albedo scheme that takes the dynamic behaviour of the surface below the green canopy into account, into the land-surface scheme of the atmosphere general circulation model ECHAM5. The scheme dynamically models the dependence of albedo on both the canopy and the surface below it, the "background". The dependence of albedo on the canopy is modelled in the way common for most GCMs, using an exponential function of LAI to define the area covered by green leaves (Beer's law; Monsi and Saeki, 1953). Background albedo is modelled as a function of the amount of soil organic matter in the bare ground and the amount of litter and standing dead biomass covering the ground, using the leaf litter and slow soil carbon pools in JSBACH as proxies for these factors. We compared the dynamic scheme with the static one for two time-slices; preindustrial and mid-Holocene.

The dynamic scheme introduces a lower albedo in the Sahel of the pre-industrial simulation and an increase in precipitation of around $30 \mathrm{~mm} / \mathrm{yr}^{-1}$ across the studied region, reducing the existing low precipitation bias of ECHAM5 within this region. The correspondence between annual mean albedo and the vegetation seen in observations is wellcaptured in the pre-industrial for both schemes, but it is only captured with the dynamic scheme for the mid-Holocene. The dynamic scheme thus gives a better estimate of albedo change than the static scheme. In the mid-Holocene, the dynamic scheme leads to an enhanced increase in precipitation of $80 \mathrm{~mm} \mathrm{yr}^{-1}$ compared to the static scheme. The sensitivity of regional precipitation to external forcing is thus increased by about one third. Albedo alone is not responsible for the northward shift and intensification of precipitation in the mid-Holocene, the orbital and SST forcings used play a major role as well. The desert albedo calculated by the dynamic scheme may inhibit the northward movement of rainfall in mid-Holocene western Sahara, since it also remains high for this time period. In the two other regions considered, albedo does not seem to be a driver of the northward shift in rainfall, rather of intensifying rainfall south of the desert border. The dynamic scheme does not just affect the sensitivity of precipitation of the whole region, it also shifts the region of large sensitivity further eastward. In western Sahara the dynamic scheme shows a lower sensitivity than the static scheme, whereas over the Red Sea and the Arabian Peninsula its sensitivity is higher. The dynamic scheme also leads to a more consistent representation of the seasonal cycle in albedo, which results in a prolongation of the rainy season in the mid-Holocene and a marked increase compared to the static scheme, especially at the beginning of the rainy season.

For both mid-Holocene simulations, the desert border is compatible with the estimated geographical extent of midHolocene lakes. However, the magnitude of rainfall is too low to sustain large lakes, although the dynamic scheme 
produces precipitation that is closer to the estimates. The results are also in disagreement with the assumption of a continuously vegetated Sahara. With the dynamic scheme, the variability in vegetation indicates the possibility of green spells. The introduction of the dynamic scheme thus results in a mid-Holocene climate that is closer to palaeo-records than the static (standard JSBACH) scheme. It also reduces the need to impose mid-Holocene boundary conditions for the albedo, allowing a more realistic representation of albedo change and the vegetation-precipitation feedback.

Acknowledgements. We would like to thank Thomas Raddatz and Thomas Kleinen as well as the two anonymous reviewers for helpful comments and suggestions.

The service charges for this open access publication have been covered by the Max Planck Society.

Edited by: P. Braconnot

\section{References}

Asner, G., Wessman, C., and Bateson, C.: Sources of variability in plant canopy hyperspectral reflectance data in a savanna ecosystem, in: Proceedings of the 7th Annual Airborne Earth Science Workshop, 1, 23-32, 1998.

Bartholomeus, H. M., Schaepman, M. E., Kooistra, L., Stevens, A., Hoogmoed, W. B., and Spaargaren, O. S. P.: Spectral reflectance based indices for soil organic carbon quantification, Geoderma, 145, 28-36, 2008.

Berger, A. L.: Long-Term Variations Of Daily Insolation And Quaternary Climatic Changes, J. Atmos. Sci., 35, 2362-2367, 1978.

Bonfils, C., de Noblet-Ducoudré, N., Braconnot, P., and Joussaume, S.: Hot desert albedo and climate change: Mid-Holocene monsoon in North Africa, J. Climate, 14, 3724-3737, 2001.

Braconnot, P., Otto-Bliesner, B., Harrison, S., Joussaume, S., Peterchmitt, J.-Y., Abe-Ouchi, A., Crucifix, M., Driesschaert, E., Fichefet, Th., Hewitt, C. D., Kageyama, M., Kitoh, A., Laîné, A., Loutre, M.-F., Marti, O., Merkel, U., Ramstein, G., Valdes, P., Weber, S. L., Yu, Y., and Zhao, Y.: Results of PMIP2 coupled simulations of the Mid-Holocene and Last Glacial Maximum Part 1: experiments and large-scale features, Clim. Past, 3, 261277, doi:10.5194/cp-3-261-2007, 2007a.

Braconnot, P., Otto-Bliesner, B., Harrison, S., Joussaume, S., Peterchmitt, J.-Y., Abe-Ouchi, A., Crucifix, M., Driesschaert, E., Fichefet, Th., Hewitt, C. D., Kageyama, M., Kitoh, A., Loutre, M.-F., Marti, O., Merkel, U., Ramstein, G., Valdes, P., Weber, L., Yu, Y., and Zhao, Y.: Results of PMIP2 coupled simulations of the Mid-Holocene and Last Glacial Maximum Part 2: feedbacks with emphasis on the location of the ITCZ and mid- and high latitudes heat budget, Clim. Past, 3, 279-296, doi:10.5194/cp-3-279-2007, 2007b.

Braconnot, P., Marzin, C., Grégoire, L., Mosquet, E., and Marti, O.: Monsoon response to changes in Earth's orbital parameters: comparisons between simulations of the Eemian and of the Holocene, Clim. Past, 4, 281-294, doi:10.5194/cp-4-281-2008, 2008.
Broström, A., Coe, M., Harrison, S. P., Gallimore, R., Kutzbach, J. E., Foley, J., Prentice, I. C., and Behling, P.: Land surface feedbacks and palaeomonsoons in northern Africa, Geophys. Res. Lett., 25, 3615-3618, 1998.

Brovkin, V., Claussen, M., Petoukhov, V., and Ganopolski, A.: On the stability of the atmosphere-vegetation system in the Sahara/Sahel region, J. Geophys. Res.-Atmos., 103, 31613-31624, 1998.

Brovkin, V., Raddatz, T., Reick, C. H., Claussen, M., and Gayler, V.: Global biogeophysical interactions between forest and climate, Geophys. Res. Lett., 36, L07405, doi:10.1029/2009GL037543, 2009.

Carrington, D. P., Gallimore, R. G., and Kutzbach, J. E.: Climate sensitivity to wetlands and wetland vegetation in mid-Holocene North Africa, Clim. Dynam., 17, 151-157, 2001.

Charney, J. G.: Dynamics Of Deserts And Drought In Sahel, Q. J. Roy. Meteor. Soc., 101, 193-202, 1975.

Claussen, M.: Modeling bio-geophysical feedback in the African and Indian monsoon region, Clim. Dynam., 13, 247-257, 1997.

Claussen, M. and Gayler, V.: The greening of the Sahara during the mid-Holocene: results of an interactive atmosphere-biome model, Global Ecol. Biogeogr., 6, 369-377, 1997.

Curran, P.: Principles of remote sensing, Longman, London and New York, 1985.

de Noblet-Ducoudre, N., Claussen, M., and Prentice, C.: Mid-Holocene greening of the Sahara: first results of the GAIM 6000 year BP Experiment with two asynchronously coupled atmosphere/biome models, Clim. Dynam., 16, 643-659, 2000.

Domingo, F., Villagarcia, L., Brenner, A. J., and Puigdefabregas, J.: Measuring and modelling the radiation balance of a heterogeneous shrubland, Plant Cell Environ., 23, 27-38, 2000.

FAO: Digital Soil Map of the World. Version 3.6., http://www.fao.org/geonetwork/srv/en/metadata.show?id= 14116\&currTab=simple (last accessed: 11 January 2011), 2007.

Fink, A. H., Christoph, M., Born, K., Bruecher, T., Piecha, K., Pohle, S., Schulz, O., Ermert, V.: Climate, in: Impacts of Global Change on the Hydrological Cycle in West and Northwest Africa, edited by: Speth, P., Christoph, M., Diekkrüger, B., Springer, Heidelberg, Germany, 54-58, 2010.

Fischer, N. and Jungclaus, J. H.: Effects of orbital forcing on atmosphere and ocean heat transports in Holocene and Eemian climate simulations with a comprehensive Earth system model, Clim. Past, 6, 155-168, doi:10.5194/cp-6-155-2010, 2010.

Gascoin, S., Ducharne, A., Ribstein, P., Perroy, E., and Wagnon, P.: Sensitivity of bare soil albedo to surface soil moisture on the moraine of the Zongo glacier (Bolivia), Geophys. Res. Lett., 36, L02405, doi:10.1029/2008GL036377, 2009.

Govaerts, Y. M., Pereira, J. M., Pinty, B., and Mota, B.: Impact of fires on surface albedo dynamics over the African continent, J. Geophys. Res.-Atmos., 107, 4629, 2002.

Henderson, T. L., Baumgardner, M. F., Franzmeier, D. P., Stott, D. E., and Coster, D. C.: High Dimensional Reflectance Analysis Of Soil Organic-Matter, Soil Sci. Soc. Am. J., 56, 865-872, 1992.

Hoelzmann, P., Jolly, D., Harrison, S. P., Laarif, F., Bonnefille, R., and Pachur, H. J.: Mid-Holocene land-surface conditions in northern Africa and the Arabian Peninsula: A data set for the analysis of biogeophysical feedbacks in the climate system, 
Global Biogeochem. Cy., 12, 35-51, 1998.

Hoelzmann, P., Kruse, H. J., and Rottinger, F.: Precipitation estimates for the eastern Saharan palaeomonsoon based on a water balance model of the West Nubian Palaeolake Basin, Global Planet. Change, 26, 105-120, 2000.

Jolly, D., Harrison, S. P., Damnati, B., and Bonnefille, R.: Simulated climate and biomes of Africa during the late quaternary: Comparison with pollen and lake status data, Quaternary Sci. Rev., 17, 629-657, 1998a.

Jolly, D., Prentice, I. C., Bonnefille, R., Ballouche, A., Bengo, M., Brenac, P., Buchet, G., Burney, D., Cazet, J. P., Cheddadi, R., Edorh, T., Elenga, H., Elmoutaki, S., Guiot, J., Laarif, F., Lamb, H., Lezine, A. M., Maley, J., Mbenza, M., Peyron, O., Reille, M., Reynaud-Farrera, I., Riollet, G., Ritchie, J. C., Roche, E., Scott, L., Ssemmanda, I., Straka, H., Umer, M., Van Campo, E., Vilimumbalo, S., Vincens, A., and Waller, M.: Biome reconstruction from pollen and plant macrofossil data for Africa and the Arabian peninsula at 0 and 6000 years, J. Biogeogr., 25, 1007-1027, 1998b.

Joussaume, S. and Braconnot, P.: Sensitivity of paleoclimate simulation results to season definitions, J. Geophys. Res.-Atmos., 102, 1943-1956, 1997.

Joussaume, S., Taylor, K. E., Braconnot, P., Mitchell, J. F. B., Kutzbach, J. E., Harrison, S. P., Prentice, I. C., Broccoli, A. J., Abe-Ouchi, A., Bartlein, P. J., Bonfils, C., Dong, B., Guiot, J., Herterich, K., Hewitt, C. D., Jolly, D., Kim, J. W., Kislov, A., Kitoh, A., Loutre, M. F., Masson, V., McAvaney, B., McFarlane, N., de Noblet, N., Peltier, W. R., Peterschmitt, J. Y., Pollard, D., Rind, D., Royer, J. F., Schlesinger, M. E., Syktus, J., Thompson, S., Valdes, P., Vettoretti, G., Webb, R. S., and Wyputta, U.: Monsoon changes for 6000 years ago: Results of 18 simulations from the Paleoclimate Modeling Intercomparison Project (PMIP), Geophys. Res. Lett., 26, 859-862, 1999.

Knorr, W. and Schnitzler, K. G.: Enhanced albedo feedback in North Africa from possible combined vegetation and soilformation processes, Clim. Dynam., 26, 55-63, 2006.

Knorr, W., Schnitzler, K. G., and Govaerts, Y.: The role of bright desert regions in shaping North African climate, Geophys. Res. Lett., 28, 3489-3492, 2001.

Kutzbach, J. E. and Liu, Z.: Response of the African monsoon to orbital forcing and ocean feedbacks in the middle Holocene, Science, 278, 440-443, 1997.

Ladoni, M., Bahrami, H. A., Alavipanah, S. K., and Norouzi, A. A.: Estimating soil organic carbon from soil reflectance: a review, Precis. Agric., 11, 82-99, 2010.

Levis, S., Bonan, G. B., and Bonfils, C.: Soil feedback drives the mid-Holocene North African monsoon northward in fully coupled CCSM2 simulations with a dynamic vegetation model, Clim. Dynam., 23, 791-802, 2004.

Lobell, D. B. and Asner, G. P.: Moisture effects on soil reflectance, Soil Sci. Soc. Am. J., 66, 722-727, 2002.

Mitchell, T. D. and Jones, P. D.: An improved method of constructing a database of monthly climate observations and associated high-resolution grids, Int. J. Climatol., 25, 693-712, 2005.

Monsi, M. and Saeki, T.: Über den Lichtfaktor in den Pflanzengesellschaften und seine Bedeutung für die Stoffproduktion, Jpn. J. Bot., 14, 22-52, 1953.
Myhre, G., Govaerts, Y., Haywood, J. M., Berntsen, T. K., and Lattanzio, A.: Radiative effect of surface albedo change from biomass burning, Geophys. Res. Lett., 32, L20812, doi:10.1029/2005GL022897, 2005.

Oleson, K., Dai, Y., Bonan, G. B., Bosilovich, M., Dickinson, R. E., Dirmeyer, P., Hoffman, F., Houser, P. R., Levis, S., Niu, G.-Y., Thornton, P., Vertenstein, M., Yang, Z.-L., and Zeng, X.: Technical Description of the Community Land Model, Tech. rep., NCAR Tech. Note TN-461+STR, National Centre for Atmospheric Research, Boulder, Colorado, 2004.

Pachur, H.-J. and Altman, N.: The Quaternary (Holocene, ca. 8000 a BP), in: Paleogeographic-paleotectonic atlas of northeastern Africa, Arabia, and adjacent areas Late Neo-Proterozoic to Holocene, edited by: Schandelmeier, H. and Reynolds, P.-O., Balkema, Rotterdam, Brookfield, 111-125, 1997.

Peters, M. and Tetzlaff, G.: The Structure Of West-African Squall Lines And Their Environmental Moisture Budget, Meteorol. Atmos. Phys., 39, 74-84, 1988.

Raddatz, T. J., Reick, C. H., Knorr, W., Kattge, J., Roeckner, E., Schnur, R., Schnitzler, K. G., Wetzel, P., and Jungclaus, J.: Will the tropical land biosphere dominate the climate-carbon cycle feedback during the twenty-first century?, Clim. Dynam., 29, 565-574, 2007.

Rechid, D., Raddatz, T., and Jacob, D.: Parameterization of snowfree land surface albedo as a function of vegetation phenology based on MODIS data and applied in climate modelling, Theor. Appl. Climatol., 95, 245-255, 2009.

Roeckner, E., Bäuml, G., Bonaventura, L., Brokopf, R., Esch, M. M. G., Hagemann, S., Kirchner, I., Kornblueh, L., Manzini, E. Rhodin, A., Schlese, U., Schulzweida, U., and Tompkins, A.: The atmospheric general circulation model ECHAM5, Part I: Model description, Tech. Rep., Max Planck Institute for Meteorology, Available from MPI for Meteorology, Hamburg, Germany, 349, 127 pp., 2003.

Samain, O., Kergoat, L., Hiernaux, P., Guichard, F., Mougin, E., Timouk, F., and Lavenu, F.: Analysis of the in situ and MODIS albedo variability at multiple timescales in the Sahel, J. Geophys Res.-Atmos., 113, D14119, doi:10.1029/2007JD009174, 2008.

Schurgers, G., Mikolajewicz, U., Groger, M., Maier-Reimer, E., Vizcaino, M., and Winguth, A.: The effect of land surface changes on Eemian climate, Clim. Dynam., 29, 357-373, 2007.

Sellers, P. J., Los, S. O., Tucker, C. J., Justice, C. O., Dazlich, D. A., Collatz, G. J., and Randall, D. A.: A revised land surface parameterization ( $\mathrm{SiB} 2$ ) for atmospheric GCMs, 2. The generation of global fields of terrestrial biophysical parameters from satellite data, J. Climate, 9, 706-737, 1996.

Stoner, E. R. and Baumgardner, M. F: Characteristic variations in reflectance of surface soils, Soil Sci. Soc. Am. J., 45(6), 11611165, 1981.

Tsvetsinskaya, E. A., Schaaf, C. B., Gao, F., Strahler, A. H., Dickinson, R. E., Zeng, X., and Lucht, W.: Relating MODIS-derived surface albedo to soils and rock types over Northern Africa and the Arabian peninsula, Geophys. Res. Lett., 29(9), 1353, doi:10.1029/2001GL014096, 2002.

Tsvetsinskaya, E. A., Schaaf, C. B., Gao, F., Strahler, A. H., and Dickinson, R. E.: Spatial and temporal variability in Moderate Resolution Imaging Spectroradiometer-derived surface albedo over global arid regions, J. Geophys. Res.-Atmos., 111, D20106, doi:10.1029/2005JD006772, 2006. 
Tucker, C. J. and Nicholson, S. E.: Variations in the size of the Sahara Desert from 1980 to 1997, Ambio, 28, 587-591, 1999.

Wang, S. S.: Dynamics of surface albedo of a boreal forest and its simulation, Ecol. Modell., 183, 477-494, 2005.
Wang, S., Trishchenko, A. P., and Sun, X. M.: Simulation of canopy radiation transfer and surface albedo in the EALCO model, Clim. Dynam., 29, 615-632, 2007.

Xue, Y. K. and Shukla, J.: The Influence Of Land-Surface Properties On Sahel Climate, 1. Desertification, J. Climate, 6, 2232 2245, 1993. 